\title{
Review
}

\section{NF- $\kappa$ B and epigenetic mechanisms as integrative regulators of brain resilience to anoxic stress}

\author{
Ilenia Sarnico ${ }^{a, 1}$, Caterina Branca $^{a, 1}$, Annamaria Lanzillotta ${ }^{a}$, Vanessa Porrini ${ }^{a}$, \\ Marina Benarese ${ }^{a}$, Pier Franco Spano ${ }^{a, b}$, Marina Pizzi ${ }^{a, b, *}$ \\ ${ }^{a}$ Department of Biomedical Sciences \& Biotechnologies, University of Brescia and Istituto Nazionale di Neuroscienze, Italy \\ bIRCCS San Camillo Hospital, Venice, Italy
}

A R T I C L E I N F O

Article history:

Accepted 9 April 2012

Keywords:

$\mathrm{NF}-\kappa \mathrm{B}$

OGD

Preconditioning

RelA acetylation

Epigenetic

Resveratrol

\begin{abstract}
A B S T R A C T
Brain cells display an amazing ability to respond to several different types of environmental stimuli and integrate this response physiologically. Some of these responses can outlive the original stimulus by days, weeks or even longer. Long-lasting changes in both physiological and pathological conditions occurring in response to external stimuli are almost always mediated by changes in gene expression. To effect these changes, cells have developed an impressive repertoire of signaling systems designed to modulate the activity of numerous transcription factors and epigenetic mechanisms affecting the chromatin structure. Since its initial characterization in the nervous system, NF- $\mathrm{kB}$ has shown to respond to multiple signals and elicit pleiotropic activities suggesting that it may play a pivotal role in integration of different types of information within the brain. Ample evidence demonstrates that NF- $\kappa B$ factors are engaged in and necessary for neuronal development and synaptic plasticity, but they also regulate brain response to environmental noxae. By focusing on the complexity of NF-кB transcriptional activity in neuronal cell death, it emerged that the composition of NF- $\mathrm{kB}$ active dimers finely tunes the neuronal vulnerability to brain ischemia. Even though we are only beginning to understand the contribution of distinct $\mathrm{NF}-\kappa \mathrm{B}$ family members to the regulation of gene transcription in the brain, an additional level of regulation of NF- $\kappa \mathrm{B}$ activity has emerged as operated by the epigenetic mechanisms modulating histone acetylation. We will discuss NF- $\mathrm{kB}$ and epigenetic mechanisms as integrative regulators of brain resilience to anoxic stress and useful drug targets for restoration of brain function.

This article is part of a Special Issue entitled Brain Integration.
\end{abstract}

(C) 2012 Elsevier B.V. All rights reserved.

\footnotetext{
* Corresponding author at: Division of Pharmacology, Department of Biomedical Sciences \& Biotechnologies, Viale Europa, 11, 25123 Brescia, Italy. Fax: +39030 3717529.

E-mail address: pizzi@med.unibs.it (M. Pizzi).

Abbreviations: CBP, p300/CREB-binding protein; HAT, histone acetyltransferase; HDAC, histone deacetylase; K310, lysine 310; MCAO, middle cerebral artery occlusion; NF-кB, nuclear factor kappa B; OGD, oxygen glucose deprivation; SIRT1, sirtuin 1

${ }^{1}$ These authors contributed equally.
} 


\section{Contents}

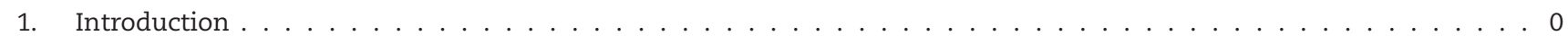

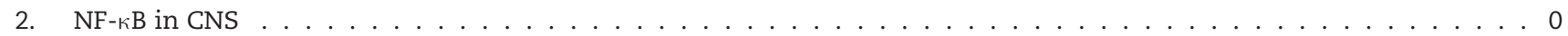

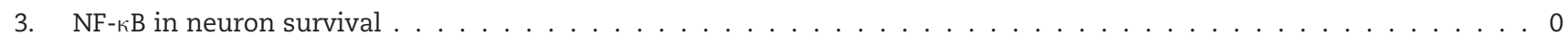

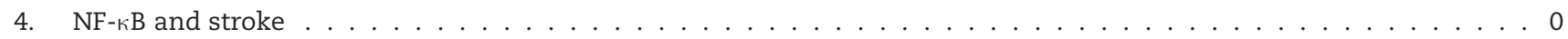

5. Epigenetic mechanisms regulate NF-кB activity in brain ischemia . . . . . . . . . . . . . . . . 0

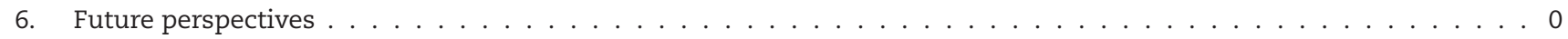

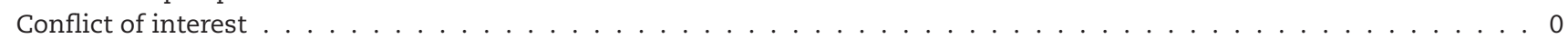

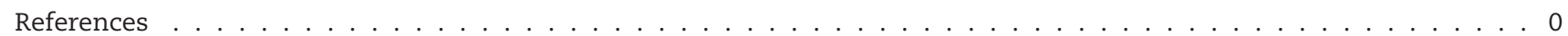

\section{Introduction}

Epigenetics is a rapidly expanding field that focuses on stable and heritable changes in gene expression that are not accompanied by changes in DNA sequence. Different definitions of epigenetics have been claimed since Waddington (1942) first coined the term in the 1940s. Nowadays the most agreed is the following: the structural adaptation of chromosomal regions so as to register signals or perpetuate altered activity states (Bird, 2007). Epigenetic machinery represents the effector of stable chromatin modifications during cell division and development, but it also represents the molecular interface mediating gene-environmental interactions during critical periods throughout the lifecycle (Fagiolini et al., 2009; Mehler, 2008). Several mechanisms contribute to the epigenetic regulation of transcriptional activity, such as DNA methylation (Laird, 2010), post translational modifications of histone proteins (Heintzman et al., 2009; Wang et al., 2008), nucleosome repositioning (Kerppola, 2009), expression of microRNA and non-coding RNAs (Guttman et al., 2009), and RNA and DNA editing (Mattick, 2009). DNA and histone modifications can affect transcription in two different ways. One is through direct alteration of the chromatin packing to open or close the DNA polymer and control the access of DNA-binding proteins such as transcription factors. The other is through alteration of the nucleosome surface to promote the association of chromatin binding proteins. It explains why the differentiated cells in a multicellular organism express only the genes that are necessary for their own activity (Berger, 2007) and require mutually reinforcing mechanisms permitting heritable patterns of gene silencing. Mutations in genes that affect global epigenetic profiles can give rise to human diseases (Egger et al., 2004). Recent studies have shed some light on the relationship between epigenetic alterations and central nervous system (CNS) disorders (De Sario, 2009; Urdinguio et al., 2009). Although CNS disorders are characterized by epigenetic persistence of an altered chromatin state, it has emerged that most of the histone modifications are reversible and can be affected by drugs. Thus, a comprehensive understanding of epigenetic mechanisms, their interactions and alterations in health and disease, has become a priority in biomedical research.

Neurodegenerative disorders create a tremendous burden on aging societies, due to their destructive nature, the number of affected individuals and the health care costs. Developing innovative therapies for neurodegenerative diseases represents a great chance to reduce disability, improve the quality of life and decrease national direct and indirect health-related costs. For this purpose, investigations on factors affecting neuronal vulnerability or resilience are considered a top priority of translational research in neurology nowadays. Among the age-related neurodegenerative disorders, the post-ischemic brain injury represents the first cause of long term disability and the second cause of death in the western world, but at the present time there is a stunning lack of efficacious treatments. Understanding the cellular and molecular machineries underlying the pathogenesis of such a devastating disorder will facilitate the development of strategies to limit brain damage and facilitate the recovery. The cellular and molecular mechanisms activated in brain ischemia are complex and not completely clarified. The involvement of the nuclear factor kappa B (NF-kB) pathway in triggering inflammatory and neurodegenerative processes has been well established, but the tools to finely dissect detrimental from beneficial NF-кB activation are still limited (Mattson and Meffert, 2006; Ridder and Schwaninger, 2009).

\section{2. $\quad \mathrm{NF}-\kappa \mathrm{B}$ in CNS}

In CNS NF- $\kappa$ B acts as regulator of growth, differentiation, and adaptive responses to extracellular signals (Kaltschmidt et al., 1993; O'Neill and Kaltschmidt, 1997; West et al., 2002). However, $\mathrm{NF}-\kappa \mathrm{B}$ activation is also involved in the pathophysiology of neurological diseases associated with neurodegeneration (Clemens et al., 1997; O'Neill and Kaltschmidt, 1997; Schneider et al., 1999), where a dual role of NF- $\mathrm{B}$ B as regulator of apoptosis has been demonstrated and widely discussed (Grilli et al., 1996; Kaltschmidt et al., 1999; Mattson and Camandola, 2001; Pizzi and Spano, 2006; Qin et al., 1999; Yu et al., 1999).

Several studies focused on the expression and regulation of NF- $\mathrm{BB}$ transcription factor in the nervous system as a pleiotropic regulator of target genes controlling physiological function. Different members of the NF-кB family have been identified in mammalian cells, these include p65 (RelA), RelB, c-Rel, p50/p105 (NF-кB1), and p52/p100 (NF-кB2). Among the members of the NF- $\kappa$ B family, only RelA, c-Rel and RelB are able to activate the transcription of target genes. The transcriptional capacity of p50 and p52, which are initially synthesized as large precursors called p105 and p100, depends on dimerization with RelA, c-Rel or RelB (Dejardin, 2006; Siebenlist et al., 1994). In the absence of stimuli, these factors are present as homo- and 
hetero-dimers bound to I $\mathrm{KB}$ family proteins. NF- $\kappa \mathrm{B}$ factors exhibit a conserved 300-aminoacid Rel homology domain (RHD), responsible for interaction with $\mathrm{I} k \mathrm{Bs}$, dimerization and binding to DNA. In stimulated cells, activation of NF-kB can occur through either a canonical or alternative pathway (Bonizzi and Karin, 2004). The canonical pathway involves signal-dependent activation of IkB kinase (IKK) complex, composed of two catalytic subunits, IKK $1 / \alpha$ and IKK2/ $\beta$, and a regulatory subunit NF-kB essential modulator (NEMO)/IKK $\gamma$. Upon stimulation, IKK2 phosphorylates two N-terminal serines within the I $\mathrm{kBs}$, leading to its proteosomal degradation and subsequent NF- $\kappa$ B release.

In the alternative pathway, IKK $\alpha$ is activated and mediates the phosphorylation of 100 followed by its ubiquitination and processing to p52 (Karin and Ben-Neriah, 2000). The subsequent translocation of NF-кB dimers to the nucleus, leads to their association with coactivators to form the transcription complex, which binds to $\mathrm{kB}$ sites with consensus sequence GGGRNNYYCC ( $\mathrm{N}=$ any base, $\mathrm{R}=$ purine, $\mathrm{Y}=$ pyrimidine) and the transcription of target genes can be activated. NF- $\kappa$ B signaling can be switched off through multiple mechanisms including I $\mathrm{B} \alpha$ protein new synthesis, a NF- $\mathrm{B}$-target gene able to bind nuclear NF- $\mathrm{kB}$ and shuttle it to the cytosol.

Over the last years new studies have emerged, suggesting that post-translational modifications of NF- $\kappa$ B, such as phosphorylation and acetylation, may represent an additional level of regulation (Hoffmann et al., 2003). The final transcriptional response is not just defined by the liberation of NF- $k B$ from I $\mathrm{B}$ but, in addition, reflects the integration of dynamic posttranslational modifications of $\mathrm{NF}-\kappa \mathrm{B}$ itself as well as the histones that surround NF-кB target genes (Chen and Greene, 2004).

\section{NF- $\kappa B$ in neuron survival}

Over the past decades the role of NF- $\mathrm{kB}$ has been intensely debated, due to the contradictory evidence that emerged from a wide investigation. Many studies supported the antiapoptotic effects of NF-кB (Koulich et al., 2001; Lezoualc'h et al., 1998; Maggirwar et al., 1998; Middleton et al., 2000) leading to neuronal resistance to excitotoxicity- (Yu et al., 1999) or A $\beta$ induced apoptosis (Kaltschmidt et al., 1999) in cultured neurons. Other studies demonstrated that the activation of $\mathrm{NF}-\kappa \mathrm{B}$ triggers neuronal degeneration after cerebral ischemia (Clemens et al., 1997; Schneider et al., 1999), mediates the glutamate-activated cell death program during excitotoxic insults to central neurons (Goffi et al., 2005; Grilli and Memo, 1999; Grilli et al., 1996; Pizzi et al., 2005a; Qin et al., 1999; Sarnico et al., 2008a) and the A $\beta$-mediated apoptosis (Valerio et al., 2006). In order to elucidate these incongruous data, we provided the first direct evidence about the dual role for NF- $\kappa B$ proteins as either cell death- or cell survival-promoting factors. In both cultured rat cerebellar granule cells and mouse hippocampal slices, we examined NF-kB activation induced by two opposing modulators of cell viability: interleukin-1 $\beta$ (IL-1 $\beta$ ), which promoted neuron survival by activating the $\mathrm{p} 50$, RelA, and c-Rel proteins, and glutamate which elicited toxicity and concomitantly activated the p50 and RelA subunits of NF-кB. We hypothesized that the balance between cell death and survival in response to external stimuli might be regulated by activation of distinct NF- $\mathrm{B}$ proteins. By using antisenseoligonucleotides, we found that the RelA knock-down reduced glutamate toxicity while the c-Rel knock-down depressed the neuroprotective activity of IL-1 $\beta$ against glutamate. Moreover, the $c-R e l$ antisense made IL- $1 \beta$ exposure per se as toxic as the glutamate one (Pizzi et al., 2002). Further investigations confirmed that $\mathrm{p} 50$ and RelA subunit activation contributes to the apoptotic program in cells exposed to the $\beta$-amyloid peptide (Akama et al., 1998; Pizzi et al., 2005b; Valerio et al., 2006). In addition, the c-Rel-containing dimers p50/c-Rel and RelA/c-Rel are involved in neuroprotective effects elicited by S100B (Kögel et al., 2004), agonists at the metabotropic glutamate type 5 (mGlu5) receptors (Pizzi et al., 2005b; Sarnico et al., 2008b) or leptin (Valerio et al., 2009). Neuroprotection elicited by c-Rel against $\beta$-amyloid toxicity was associated with the expression of the antiapoptotic proteins B-cell lymphomaextra large $\left(\mathrm{Bcl}-\mathrm{x}_{\mathrm{L}}\right)$ and manganese superoxide dismutase (MnSOD) (Pizzi et al., 2005b) (Fig. 1A).

\section{NF- $\kappa$ B and stroke}

Extracellular stimuli that activate the NF- $\mathrm{BB}$ pathway include proinflammatory cytokines, physical and oxidative stress, apoptotic mediators, elevation of intracellular calcium levels and excitotoxicity (Barnes and Karin, 1997; Ghosh et al., 1998; Siebenlist et al., 1994), many of which have been implicated in pathogenesis of post-ischemic injury (Crack et al., 2006; Herrmann et al., 2005; Nurmi et al., 2004; Schneider et al., 1999). In severe ischemia, NF-кB contributes to neuronal cell death program leading to irreversible brain damage. In contrast, in sublethal ischemia NF- $\mathrm{BB}$ contributes to the preconditioning effect by dampening its own subsequent full activation through the activation of IkB $\alpha$ transcription (Blondeau et al., 2001; Ridder and Schwaninger, 2009).

We afforded the dual effect of NF- $\kappa$ B activation in preconditioning and lethal ischemia using neuronal cells exposed to oxygen glucose deprivation (OGD) and mice subjected to middle cerebral artery occlusion (MCAO) (Lanzillotta et al., 2010; Pizzi et al., 2009). After exposure to lethal ischemia, neuronal nuclei displayed a high level of p50/RelA activation (Crack et al., 2006; Inta et al., 2006) and decreased level of c-Relcontaining dimers (Sarnico et al., 2009a, 2009b). Accordingly, mice deficient in p50 or RelA, but not mice deficient in c-Rel subunit, showed a reduced infarct size when exposed to MCAO (Inta et al., 2006; Schneider et al., 1999). The specific activation of NF- $\kappa$ B was associated with an unbalanced expression of NF$\kappa \mathrm{B}$ target genes belonging to the $\mathrm{Bcl}-2$ family regulators of apoptosis. Mostly, the pro-apoptotic members Bim and Noxa, under the transcriptional control of RelA, increased in cortical neurons of ischemic mice (Inta et al., 2006), while the antiapoptotic member Bcl- $x_{L}$ decreased (Cao et al., 2002; Sarnico et al., 2009a). The overexpression of RelA worsened cell death. The overexpression of c-Rel prevented the neuronal loss after ischemic injury by increasing the transcription of $B c l-x_{L}$ gene (Pizzi et al., 2009; Sarnico et al., 2009a). Furthermore, the adipocyte-derived hormone leptin, by activating c-Relcontaining dimers c-Rel/p50 and c-Rel/RelA, significantly increased $B c l-x_{L}$ expression and reduced the infarct volume 
A
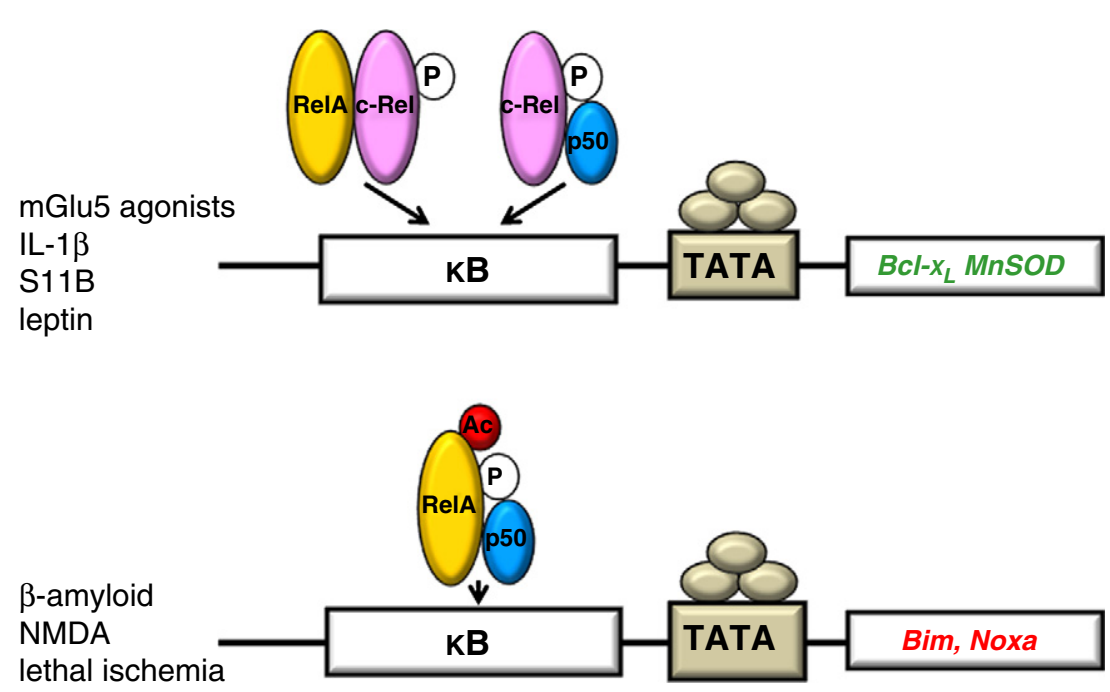

B

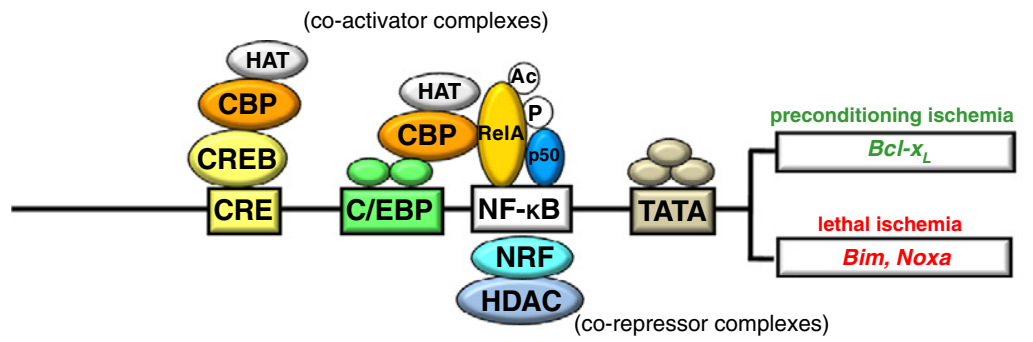

preconditioning ischemia

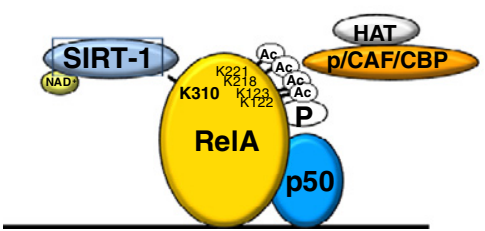

Neuroprotection

lethal ischemia

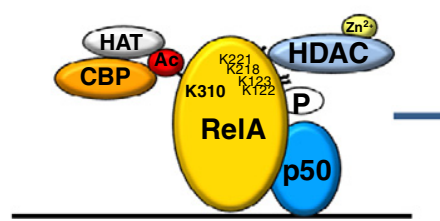

Cell death

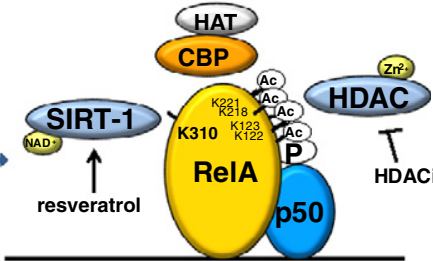

Neuroprotection

Fig. 1 - NF- $\kappa B$ dimer composition and post-transcriptional modifications of NF- $\kappa$ B subunits represent diverse levels of regulation of NF- $\kappa B$ activity in response to environmental stimuli affecting neuron survival. A). The c-Rel-containing dimers, p50/c-Rel and RelA/c-Rel, mediate neuroprotective effects elicited by interleukin-1 $\beta$, mGlu5 receptor agonists, S100B and leptin through the induction of anti-apoptotic gene expression. Activation of p50/RelA dimer mediates the neurotoxic effects elicited by NMDA, $\beta$-amyloid and lethal ischemia through the transcription of pro-apoptotic genes. B). The p50/RelA dimer is rapidly induced either by prolonged lethal ischemia or by brief, preconditioning ischemia. However, the acetylation state of nuclear RelA is different in the two conditions. In preconditioning ischemia, RelA is highly acetylated on its lysine residues with the exclusion of the $\mathrm{K} 310$. After prolonged ischemia, the RelA undergoes a general lysine deacetylation but its acetylation on $\mathrm{K} 310$ increases. CBP-RelA interaction is higher in lethal ischemia than in preconditioning ischemia. HDAC inhibitors in association with resveratrol could maintain the NF- $\kappa B$ activation and switch the RelA acetylation toward its "preconditioning profile", thus producing neuroprotection. CRE, cAMP responsive element; CREB, CRE binding protein; CBP, p300/CREB-binding protein; C/EBP, CCAAT-enhancer-binding protein; p/CAF, p300/CBP-associated factor; HAT, histone acetyltransferase; HDAC, histone

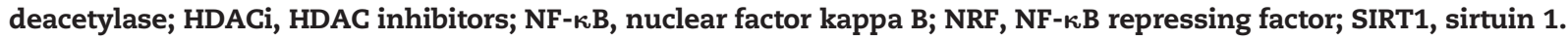

in mice exposed to permanent MCAO. As a confirmation of the pivotal role of c-Rel in limiting apoptosis, the protective effect of leptin in brain ischemia was suppressed in c-Rel deficient mice (Valerio et al., 2009).

All these data strongly supported the view that in lethal ischemia the activation of p50/RelA dimer and the concomitant deactivation of c-Rel-containing dimers are key events in the pathogenesis of post-ischemic brain injury. What remained to be clarified was the mechanism of neuroprotection elicited by NF- $\mathrm{kB}$ in preconditioning ischemia (Blondeau et al., 2001). Indeed, a similar pattern of p50/RelA without c-Rel activation was found in brains of mice exposed to preconditioning or lethal ischemia (Lanzillotta et al., 2010). This suggested that the nuclear translocation of p50/RelA 
was not sufficient to specify the pro-apoptotic program during ischemia and that mechanisms shaping the p50/RelA transcriptional activity could be responsible for a dual effect of NF-kB. In line with this view, studies in tumor cells had showed that the RelA subunit acts as an inducer of antiapoptotic gene expression, but under certain circumstances it is able to repress the same target genes (Campbell and Perkins, 2004; Rocha et al., 2005). A possible solution to the Doctor Jekyll and Mister Hyde performance of p50/RelA is to be sought in epigenetics.

\section{Epigenetic mechanisms regulate NF- $\kappa B$ activity in brain ischemia}

Recent findings are delineating that acetylation of histone and non-histone proteins is involved directly and indirectly in controlling the duration, strength and specificity of the NF- $\kappa$ Bactivity at multiple levels (Aguilera et al., 2004; Viatour et al., 2003; Yamamoto et al., 2003). Acetylation and deacetylation events, in combination with other post-translational protein modifications, generate 'NF- $\mathrm{B}$-signaling code' and regulate NF$\kappa \mathrm{B}$-dependent gene transcription in an inducer- and promoterdependent manner. Indeed, the intricate involvement of histone acetyltransferases (HAT) and histone deacetylases (HDAC) modulates both the NF-кB-signaling pathway and the transactivation of NF-кB-dependent genes (Chen et al., 2001, 2005; Furia et al., 2002; Hoberg et al., 2006; Kiernan et al., 2003; Mittal et al., 2006; Yeung et al., 2004).

Acetylation of RelA is a dynamic process where the acetylation status of specific lysine residues affects both the DNA-binding ability and transcriptional activity of the protein (Chen et al., 2002; Kiernan et al., 2003).

Once in the nucleus, RelA subunit is phosphorylated at distinct serine residues and then activates transcription by interacting with HAT co-activators, including p300/CREB binding protein (p300/CBP), the steroid receptor-coactivator-1, and the p300/CBP-associated factor (p/CAF) (Gerritsen et al., 1997; Perkins et al., 1997; Zhong et al., 1998). Besides acetylating the $\mathrm{N}$-terminal tails of core histones surrounding NF-кB-regulated genes, HATs are directly responsible for RelA acetylation. This effect is believed to facilitate an 'open chromatin' configuration, allowing transcription (Mayo et al., 2003). Site-specific acetylation of NF- $\kappa B$ RelA at multiple lysines (K122, 123, 218, 221, and 310) can differently affect the interaction with $\mathrm{I}_{\kappa} \mathrm{B} \alpha$, the DNA-binding or the transcriptional activity of the factor (Chen and Greene, 2004; Kiernan et al., 2003).

In addition to co-activators, RelA also recruits co-repressor complexes, endowed with deacetylase activity. Members of the class I HDAC (HDAC1, HDAC2, and HDAC3) deacetylate RelA, resulting in increased $\mathrm{I} \kappa \mathrm{B} \alpha$ association and loss of transactivation potential of the factor (Ashburner et al., 2001; Chen and Greene, 2004; Zhong et al., 2002). Sirtuins, homologs of the yeast SIR2 family, belong to the atypical class III HDACs (Frye, 2000) and require nicotinamide adenosine dinucleotide $\left(\mathrm{NAD}^{+}\right.$) as a cofactor (Buck et al., 2004). While the members of class I HDACs are the most responsible for general RelA deacetylation, sirtuin 1 (SIRT1) selectively deacetylates RelA at K310 (Yeung et al., 2004).
Recently, we tested whether epigenetic mechanisms affecting the acetylation state of histones and RelA might discriminate between preconditioning and neurotoxic activation of NF- $\kappa B$ during ischemia. In ischemic cortices of mice subjected to MCAO, as well as in cortical neurons exposed to lethal OGD, activated RelA displayed a high level of K310 acetylation in spite of a reduced level of total lysine acetylation. Conversely, RelA activated during preconditioning ischemia conserved its general acetylation, but showed a specific deacetylation on the $\mathrm{K} 310$ residue. CBP strongly interacted with RelA during lethal ischemia, while the interaction was reduced in preconditioning ischemia, indicating a role for this HAT moiety in the process of site-specific acetylation on RelA K310 (Fig. 1B). Molecular manipulation of RelA acetylation through expression of an acetylation resistant RelA-K310-R mutant construct, or the pharmacological deacetylation of RelA on K310 by the SIRT1 activator resveratrol, reduced Bim promoter activity during OGD and reduced cell death (Lanzillotta et al., 2010).

These results give evidence of the role of RelA acetylation in driving cell decision to either fight or capitulate to ischemic challenge. The acetylation of RelA in K310 dictates NF-кBdependent pro-apoptotic and pro-inflammatory responses (Chen et al., 2002, 2005) and may represent a suitable target to dissect pathological from neuroprotective activation of $\mathrm{NF}-\kappa \mathrm{B}$ in brain ischemia.

\section{Future perspectives}

The identification of molecular mechanisms shaping activation and transcriptional activity of diverse NF- $\kappa$ B dimers in the brain will unravel new potential targets to treat neurological diseases associated with inflammation and apoptotic cell death. The derangement of RelA acetylation, in particular, may represent a new drugable target to design efficient therapies aimed at limiting brain damage while preserving the integrative activity of $\mathrm{NF}-\kappa \mathrm{B}$ in regulating immune and cognitive functions. The goal of this therapeutic approach should be to increase the general lysine acetylation of RelA and achieve its specific deacetylation at K310.

RelA acetylation can be modified by using HDAC inhibitors that have already proved to be effective in attenuating neurological deficits and neuronal loss in various animal models of brain ischemia (Kim et al., 2007; Ren et al., 2004), Huntington's disease (Ferrante et al., 2003; Gardian et al., 2005; Hockly et al., 2003), spinal muscular atrophy (Chang et al., 2001), amyotrophic lateral sclerosis (Corcoran et al., 2004; Petri et al., 2006; Ryu et al., 2005), and experimental autoimmune encephalomyelitis (Camelo et al., 2005). Among HDAC inhibitors, suberoylanilide hydroxamic acid (SAHA), trichostatin A (TSA) and MS-275 (entinostat) are effective in inhibiting the HDAC1, HDAC2 and HDAC3 isoforms (Blackwell et al., 2008) that are the most involved in RelA deacetylation (Ashburner et al., 2001; Chen and Greene, 2004; Zhong et al., 2002). On the other side, the specific deacetylation of RelA at the K310 residue could be achieved by using the SIRT1 activator resveratrol which reduces pro-apoptotic transcription and rescues neuronal cells from apoptosis (Lanzillotta et al., 2010). The association of such drugs endowed with 
different mechanisms of action and targeting both histones and aberrant RelA acetylation, might unravel a new therapeutic approach to treat neurodegenerative disorders by preserving neural integrative functions and sustain brain restoration.

The epigenetic machinery that regulates acetylation of histones, transcription factors and DNA is intimately involved in synaptic plasticity, learning and memory and age-related neurodegenerative disorders. Therapies, aimed to correct the dysfunction in chromatin plasticity and the activity of NF- $\kappa \mathrm{B}$ transcription factor may represent a new challenge for effective "disease modifying" strategies.

\section{Conflict of interest}

The authors declare no conflict of interest.

\section{R E F ERENCES}

Aguilera, C., Hoya-Arias, R., Haegeman, G., Espinosa, L., Bigas, A., 2004. Recruitment of IkappaBalpha to the hes1 promoter is associated with transcriptional repression. Proc. Natl. Acad. Sci. U. S. A. 101, 16537-16542.

Akama, K.T., Albanese, C., Pestell, R.G., Van Eldik, L.J., 1998. Amyloid beta-peptide stimulates nitric oxide production in astrocytes through an NFkappaB-dependent mechanism. Proc. Natl. Acad. Sci. U. S. A. 95, 5795-5800.

Ashburner, B.P., Westerheide, S.D., Baldwin Jr., A.S., 2001. The p65 (RelA) subunit of NF-kappaB interacts with the histone deacetylase (HDAC) corepressors HDAC1 and HDAC2 to negatively regulate gene expression. Mol. Cell. Biol. 21, 7065-7077.

Barnes, P.J., Karin, M., 1997. Nuclear factor-kappaB: a pivotal transcription factor in chronic inflammatory diseases. N. Engl. J. Med. 336, 1066-1071.

Berger, S.L., 2007. The complex language of chromatin regulation during transcription. Nature 447, 407-412.

Bird, A., 2007. Perceptions of epigenetics. Nature 447, 396-398.

Blackwell, L., Norris, J., Suto, C.M., Janzen, W.P., 2008. The use of diversity profiling to characterize chemical modulators of the histone deacetylases. Life Sci. 82, 1050-1058.

Blondeau, N., Widmann, C., Lazdunski, M., Heurteaux, C., 2001. Activation of the nuclear factor-kappaB is a key event in brain tolerance. J. Neurosci. 21, 4668-4677.

Bonizzi, G., Karin, M., 2004. The two NF-kappaB activation pathways and their role in innate and adaptive immunity. Trends Immunol. 25, 280-288.

Buck, S.W., Gallo, C.M., Smith, J.S., 2004. Diversity in the Sir2 family of protein deacetylases. J. Leukoc. Biol. 75, 939-950.

Camelo, S., Iglesias, A.H., Hwang, D., Due, B., Ryu, H., Smith, K., Gray, S.G., Imitola, J., Duran, G., Assaf, B., Langley, B., Khoury, S.J., Stephanopoulos, G., De Girolami, U., Ratan, R.R., Ferrante, R.J., Dangond, F., 2005. Transcriptional therapy with the histone deacetylase inhibitor trichostatin A ameliorates experimental autoimmune encephalomyelitis. J. Neuroimmunol. 164, 10-21.

Campbell, K.J., Perkins, N.D., 2004. Reprogramming RelA. Cell Cycle 3, 869-872.

Cao, G., Pei, W., Ge, H., Liang, Q., Luo, Y., Sharp, F.R., Lu, A., Ran, R., Graham, S.H., Chen, J., 2002. In vivo delivery of a Bcl-xL fusion protein containing the TAT protein transduction domain protects against ischemic brain injury and neuronal apoptosis. J. Neurosci. 22, 5423-5431.
Chang, J.G., Hsieh-Li, H.M., Jong, Y.J., Wang, N.M., Tsai, C.H., Li, H., 2001. Treatment of spinal muscular atrophy by sodium butyrate. Proc. Natl. Acad. Sci. U. S. A. 98, 9808-9813.

Chen, L.F., Greene, W.C., 2004. Shaping the nuclear action of NF-kappaB. Nat. Rev. Mol. Cell Biol. 5, 392-401.

Chen, L.F., Fischle, W., Verdin, E., Greene, W.C., 2001. Duration of nuclear NF-kappaB action regulated by reversible acetylation. Science 293, 1653-1657.

Chen, L.F., Mu, Y., Greene, W.C., 2002. Acetylation of RelA at discrete sites regulates distinct nuclear functions of NF-kappaB. EMBO J. 21, 6539-6548.

Chen, L.F., Williams, S.A., Mu, Y., Nakano, H., Duerr, J.M., Buckbinder, L., Greene, W.C., 2005. NF-kappaB RelA phosphorylation regulates RelA acetylation. Mol. Cell. Biol. 25, 7966-7975.

Clemens, J.A., Stephenson, D.T., Smalstig, E.B., Dixon, E.P., Little, S.P., 1997. Global ischemia activates nuclear factor-kappa B in forebrain neurons of rats. Stroke 28, 1073-1081.

Corcoran, L.J., Mitchison, T.J., Liu, Q., 2004. A novel action of histone deacetylase inhibitors in a protein aggresome disease model. Curr. Biol. 14, 488-492.

Crack, P.J., Taylor, J.M., Ali, U., Mansell, A., Hertzog, P.J., 2006. Potential contribution of NF-kappaB in neuronal cell death in the glutathione peroxidase-1 knockout mouse in response to ischemia-reperfusion injury. Stroke 37, 1533-1538.

De Sario, A., 2009. Clinical and molecular overview of inherited disorders resulting from epigenomic dysregulation. Eur. J. Med. Genet. 52, 363-372.

Dejardin, E., 2006. The alternative NF-kappaB pathway from biochemistry to biology: pitfalls and promises for future drug development. Biochem. Pharmacol. 72, 1161-1179.

Egger, G., Liang, G., Aparicio, A., Jones, P.A., 2004. Epigenetics in human disease and prospects for epigenetic therapy. Nature 429, 457-463.

Fagiolini, M., Jensen, C.L., Champagne, F.A., 2009. Epigenetic influences on brain development and plasticity. Curr. Opin. Neurobiol. 19, 207-212.

Ferrante, R.J., Kubilus, J.K., Lee, J., Ryu, H., Beesen, A., Zucker, B., Smith, K., Kowall, N.W., Ratan, R.R., Luthi-Carter, R., Hersch, S.M., 2003. Histone deacetylase inhibition by sodium butyrate chemotherapy ameliorates the neurodegenerative phenotype in Huntington's disease mice. J. Neurosci. 23, 9418-9427.

Frye, R.A., 2000. Phylogenetic classification of prokaryotic and eukaryotic Sir2-like proteins. Biochem. Biophys. Res. Commun. 273, 793-798.

Furia, B., Deng, L., Wu, K., Baylor, S., Kehn, K., Li, H., Donnelly, R., Coleman, T., Kashanchi, F., 2002. Enhancement of nuclear factor-kappa B acetylation by coactivator p300 and HIV-1 Tat proteins. J. Biol. Chem. 277, 4973-4980.

Gardian, G., Browne, S.E., Choi, D.K., Klivenyi, P., Gregorio, J., Kubilus, J.K., Ryu, H., Langley, B., Ratan, R.R., Ferrante, R.J., Beal, M.F., 2005. Neuroprotective effects of phenylbutyrate in the N171-82Q transgenic mouse model of Huntington's disease. J. Biol. Chem. 280, 556-563.

Gerritsen, M.E., Williams, A.J., Neish, A.S., Moore, S., Shi, Y., Collins, T., 1997. CREB-binding protein/p300 are transcriptional coactivators of p65. Proc. Natl. Acad. Sci. U. S. A. 94, 2927-2932.

Ghosh, S., May, M.J., Kopp, E.B., 1998. NF-kappa B and Rel proteins: evolutionarily conserved mediators of immune responses. Annu. Rev. Immunol. 16, 225-260.

Goffi, F., Boroni, F., Benarese, M., Sarnico, I., Benetti, A., Spano, P.F., Pizzi, M., 2005. The inhibitor of I kappa B alpha phosphorylation BAY 11-7082 prevents NMDA neurotoxicity in mouse hippocampal slices. Neurosci. Lett. 377, 147-151.

Grilli, M., Memo, M., 1999. Possible role of NF-kappaB and p53 in the glutamate-induced pro-apoptotic neuronal pathway. Cell Death Differ. 6, 22-27.

Grilli, M., Pizzi, M., Memo, M., Spano, P., 1996. Neuroprotection by aspirin and sodium salicylate through blockade of NF-kappaB activation. Science 274, 1383-1385. 
Guttman, M., Amit, I., Garber, M., French, C., Lin, M.F., Feldser, D., Huarte, M., Zuk, O., Carey, B.W., Cassady, J.P., Cabili, M.N., Jaenisch, R., Mikkelsen, T.S., Jacks, T., Hacohen, N., Bernstein, B.E., Kellis, M., Regev, A., Rinn, J.L., Lander, E.S., 2009.

Chromatin signature reveals over a thousand highly conserved large non-coding RNAs in mammals. Nature 458, 223-227.

Heintzman, N.D., Hon, G.C., Hawkins, R.D., Kheradpour, P., Stark, A., Harp, L.F., Ye, Z., Lee, L.K., Stuart, R.K., Ching, C.W., Ching, K.A., Antosiewicz-Bourget, J.E., Liu, H., Zhang, X., Green, R.D., Lobanenkov, V.V., Stewart, R., Thomson, J.A., Crawford, G.E., Kellis, M., Ren, B., 2009. Histone modifications at human enhancers reflect global cell-type-specific gene expression. Nature 459, 108-112.

Herrmann, O., Baumann, B., de Lorenzi, R., Muhammad, S., Zhang, W., Kleesiek, J., Malfertheiner, M., Köhrmann, M., Potrovita, I., Maegele, I., Beyer, C., Burke, J.R., Hasan, M.T., Bujard, H., Wirth, T., Pasparakis, M., Schwaninger, M., 2005. IKK mediates ischemia-induced neuronal death. Nat. Med. 11, 1322-1329.

Hoberg, J.E., Popko, A.E., Ramsey, C.S., Mayo, M.W., 2006. IkappaB kinase alpha-mediated derepression of SMRT potentiates acetylation of RelA/p65 by p300. Mol. Cell. Biol. 26, 457-471.

Hockly, E., Richon, V.M., Woodman, B., Smith, D.L., Zhou, X., Rosa, E., Sathasivam, K., Ghazi-Noori, S., Mahal, A., Lowden, P.A., Steffan, J.S., Marsh, J.L., Thompson, L.M., Lewis, C.M., Marks, P.A., Bates, G.P., 2003. Suberoylanilide hydroxamic acid, a histone deacetylase inhibitor, ameliorates motor deficits in a mouse model of Huntington's disease. Proc. Natl. Acad. Sci. U. S. A. 100, 2041-2046.

Hoffmann, A., Leung, T.H., Baltimore, D., 2003. Genetic analysis of NF-kappaB/Rel transcription factors defines functional specificities. EMBO J. 22, 5530-5539.

Inta, I., Paxian, S., Maegele, I., Zhang, W., Pizzi, M., Spano, P., Sarnico, I., Muhammad, S., Herrmann, O., Inta, D., Baumann, B., Liou, H.C., Schmid, R.M., Schwaninger, M., 2006. Bim and Noxa are candidates to mediate the deleterious effect of the NF-kappa B subunit RelA in cerebral ischemia. J. Neurosci. 26, 12896-12903.

Kaltschmidt, C., Kaltschmidt, B., Baeuerle, P.A., 1993. Brain synapses contain inducible forms of the transcription factor NF-kappa B. Mech. Dev. 43, 135-147.

Kaltschmidt, B., Uherek, M., Wellmann, H., Volk, B., Kaltschmidt, C., 1999. Inhibition of NF-kappaB potentiates amyloid beta-mediated neuronal apoptosis. Proc. Natl. Acad. Sci. U. S. A. 96, 9409-9414.

Karin, M., Ben-Neriah, Y., 2000. Phosphorylation meets ubiquitination: the control of NF-kappaB activity. Annu. Rev. Immunol. 18, 621-663.

Kerppola, T.K., 2009. Polycomb group complexes-many combinations, many functions. Trends Cell Biol. 19, 692-704.

Kiernan, R., Brès, V., Ng, R.W., Coudart, M.P., El Messaoudi, S., Sardet, C., Jin, D.Y., Emiliani, S., Benkirane, M., 2003. Post-activation turn-off of NF-kappa B-dependent transcription is regulated by acetylation of p65. J. Biol. Chem. 278, 2758-2766.

Kim, H.J., Rowe, M., Ren, M., Hong, J.S., Chen, P.S., Chuang, D.M., 2007. Histone deacetylase inhibitors exhibit anti-inflammatory and neuroprotective effects in a rat permanent ischemic model of stroke: multiple mechanisms of action. J. Pharmacol. Exp. Ther. 321, 892-901.

Kögel, D., Peters, M., König, H.G., Hashemi, S.M., Bui, N.T., Arolt, V., Rothermundt, M., Prehn, J.H., 2004. S100B potently activates p65/c-Rel transcriptional complexes in hippocampal neurons: clinical implications for the role of S100B in excitotoxic brain injury. Neuroscience 127, 913-920.

Koulich, E., Nguyen, T., Johnson, K., Giardina, C., D'mello, S., 2001. NF-kappaB is involved in the survival of cerebellar granule neurons: association of IkappaB $\beta$ phosphorylation with cell survival. J. Neurochem. 76, 1188-1198.

Laird, P.W., 2010. Principles and challenges of genomewide DNA methylation analysis. Nat. Rev. Genet. 11, 191-203.
Lanzillotta, A., Sarnico, I., Ingrassia, R., Boroni, F., Branca, C., Benarese, M., Faraco, G., Blasi, F., Chiarugi, A., Spano, P., Pizzi, M., 2010. The acetylation of RelA in Lys310 dictates the NF-кB-dependent response in post-ischemic injury. Cell Death Dis. 1, e96.

Lezoualc'h, F., Sagara, Y., Holsboer, F., Behl, C., 1998. High constitutive NF-kappaB activity mediates resistance to oxidative stress in neuronal cells. J. Neurosci. 18, 3224-3232.

Maggirwar, S.B., Sarmiere, P.D., Dewhurst, S., Freeman, R.S., 1998. Nerve growth factor-dependent activation of NF-kappaB contributes to survival of sympathetic neurons. J. Neurosci. 18, 10356-10365.

Mattick, J.S., 2009. Deconstructing the dogma: a new view of the evolution and genetic programming of complex organisms. Ann. N. Y. Acad. Sci. 1178, 29-46.

Mattson, M.P., Camandola, S., 2001. NF-kappaB in neuronal plasticity and neurodegenerative disorders. J. Clin. Invest. 107, 247-254

Mattson, M.P., Meffert, M.K., 2006. Roles for NF-kappaB in nerve cell survival, plasticity, and disease. Cell Death Differ. 13, 852-860.

Mayo, M.W., Denlinger, C.E., Broad, R.M., Yeung, F., Reilly, E.T., Shi, Y., Jones, D.R., 2003. Ineffectiveness of histone deacetylase inhibitors to induce apoptosis involves the transcriptional activation of NF-kappa B through the Akt pathway. J. Biol. Chem. 278, 18980-18989.

Mehler, M.F., 2008. Epigenetic principles and mechanisms underlying nervous system functions in health and disease. Prog. Neurobiol. 86, 305-341.

Middleton, G., Hamanoue, M., Enokido, Y., Wyatt, S., Pennica, D., Jaffray, E., Hay, R.T., Davies, A.M., 2000. Cytokine-induced nuclear factor kappa B activation promotes the survival of developing neurons. J. Cell Biol. 148, 325-332.

Mittal, R., Peak-Chew, S.Y., McMahon, H.T., 2006. Acetylation of MEK2 and I kappa B kinase (IKK) activation loop residues by YopJ inhibits signaling. Proc. Natl. Acad. Sci. U. S. A. 103, 18574-18579.

Nurmi, A., Lindsberg, P.J., Koistinaho, M., Zhang, W., Juettler, E., Karjalainen-Lindsberg, M.L., Weih, F., Frank, N., Schwaninger, M., Koistinaho, J., 2004. Nuclear factor-kappaB contributes to infarction after permanent focal ischemia. Stroke 35, 987-991.

O’Neill, L.A., Kaltschmidt, C., 1997. NF-kappa B: a crucial transcription factor for glial and neuronal cell function. Trends Neurosci. 20, 252-258.

Perkins, N.D., Felzien, L.K., Betts, J.C., Leung, K., Beach, D.H., Nabel, G.J., 1997. Regulation of NF-kappaB by cyclin-dependent kinases associated with the p300 coactivator. Science 275, 523-527.

Petri, S., Kiaei, M., Kipiani, K., Chen, J., Calingasan, N.Y., Crow, J.P., Beal, M.F., 2006. Additive neuroprotective effects of a histone deacetylase inhibitor and a catalytic antioxidant in a transgenic mouse model of amyotrophic lateral sclerosis. Neurobiol. Dis. 22, $40-49$.

Pizzi, M., Spano, P., 2006. Distinct roles of diverse nuclear factor-kappaB complexes in neuropathological mechanisms. Eur. J. Pharmacol. 545, 22-28.

Pizzi, M., Goffi, F., Boroni, F., Benarese, M., Perkins, S.E., Liou, H.C., Spano, P., 2002. Opposing roles for NF-kappa B/Rel factors p65 and c-Rel in the modulation of neuron survival elicited by glutamate and interleukin-1beta. J. Biol. Chem. 277, 20717-20723.

Pizzi, M., Sarnico, I., Boroni, F., Benetti, A., Benarese, M., Spano, P.F., 2005a. Inhibition of IkappaBalpha phosphorylation prevents glutamate-induced NF-kappaB activation and neuronal cell death. Acta Neurochir. Suppl. 93, 59-63.

Pizzi, M., Sarnico, I., Boroni, F., Benarese, M., Steimberg, N., Mazzoleni, G., Dietz, G.P., Bähr, M., Liou, H.C., Spano, P.F., 2005b. NF-kappaB factor c-Rel mediates neuroprotection elicited by mGlu5 receptor agonists against amyloid beta-peptide toxicity. Cell Death Differ. 12, 761-772. 
Pizzi, M., Sarnico, I., Lanzillotta, A., Battistin, L., Spano, P., 2009. Post-ischemic brain damage: NF-kappaB dimer heterogeneity as a molecular determinant of neuron vulnerability. FEBS J. 276, 27-35.

Qin, Z.H., Chen, R.W., Wang, Y., Nakai, M., Chuang, D.M., Chase, T.N., 1999. Nuclear factor kappaB nuclear translocation upregulates c-Myc and p53 expression during NMDA receptor-mediated apoptosis in rat striatum. J. Neurosci. 19, 4023-4033.

Ren, M., Leng, Y., Jeong, M., Leeds, P.R., Chuang, D.M., 2004. Valproic acid reduces brain damage induced by transient focal cerebral ischemia in rats: potential roles of histone deacetylase inhibition and heat shock protein induction. J. Neurochem. 89, 1358-1367.

Ridder, D.A., Schwaninger, M., 2009. NF-kappaB signaling in cerebral ischemia. Neuroscience 158, 995-1006.

Rocha, S., Garrett, M.D., Campbell, K.J., Schumm, K., Perkins, N.D., 2005. Regulation of NF-kappaB and p53 through activation of ATR and Chk1 by the ARF tumour suppressor. EMBO J. 24, 1157-1169.

Ryu, H., Smith, K., Camelo, S.I., Carreras, I., Lee, J., Iglesias, A.H., Dangond, F., Cormier, K.A., Cudkowicz, M.E., Brown Jr., R.H., Ferrante, R.J., 2005. Sodium phenylbutyrate prolongs survival and regulates expression of anti-apoptotic genes in transgenic amyotrophic lateral sclerosis mice. J. Neurochem. 93, 1087-1098.

Sarnico, I., Boroni, F., Benarese, M., Alghisi, M., Valerio, A., Battistin, L., Spano, P., Pizzi, M., 2008a. Targeting IKK2 by pharmacological inhibitor AS602868 prevents excitotoxic injury to neurons and oligodendrocytes. J. Neural. Transm. 115, 693-701.

Sarnico, I., Boroni, F., Benarese, M., Sigala, S., Lanzillotta, A., Battistin, L., Spano, P., Pizzi, M., 2008b. Activation of NF-kappaB p65/c-Rel dimer is associated with neuroprotection elicited by mGlu5 receptor agonists against $\mathrm{MPP}(+)$ toxicity in SK-N-SH cells. J. Neural. Transm. 115, 669-676.

Sarnico, I., Lanzillotta, A., Boroni, F., Benarese, M., Alghisi, M., Schwaninger, M., Inta, I., Battistin, L., Spano, P., Pizzi, M., 2009a. NF-kappaB p50/RelA and c-Rel-containing dimers: opposite regulators of neuron vulnerability to ischaemia. J. Neurochem. 108, 475-485.

Sarnico, I., Lanzillotta, A., Benarese, M., Alghisi, M., Baiguera, C., Battistin, L., Spano, P., Pizzi, M., 2009b. NF-kappaB dimers in the regulation of neuronal survival. Int. Rev. Neurobiol. 85, 351-362 (Review).

Schneider, A., Martin-Villalba, A., Weih, F., Vogel, J., Wirth, T., Schwaninger, M., 1999. NF-kappaB is activated and promotes cell death in focal cerebral ischemia. Nat. Med. 5, 554-559.
Siebenlist, U., Franzoso, G., Brown, K., 1994. Structure, regulation and function of NF-kappa B. Annu. Rev. Cell Biol. 10, 405-455.

Urdinguio, R.G., Sanchez-Mut, J.V., Esteller, M., 2009. Epigenetic mechanisms in neurological diseases: genes, syndromes, and therapies. Lancet Neurol. 8, 1056-1072.

Valerio, A., Boroni, F., Benarese, M., Sarnico, I., Ghisi, V., Bresciani, L.G., Ferrario, M., Borsani, G., Spano, P., Pizzi, M., 2006. NF-kappaB pathway: a target for preventing beta-amyloid (Abeta)-induced neuronal damage and Abeta42 production. Eur. J. Neurosci. 23, 1711-1720.

Valerio, A., Dossena, M., Bertolotti, P., Boroni, F., Sarnico, I., Faraco, G., Chiarugi, A., Frontini, A., Giordano, A., Liou, H.C., De Simoni, M.G., Spano, P., Carruba, M.O., Pizzi, M., Nisoli, E., 2009. Leptin is induced in the ischemic cerebral cortex and exerts neuroprotection through NF-kappaB/c-Rel-dependent transcription. Stroke 40, 610-617.

Viatour, P., Legrand-Poels, S., van Lint, C., Warnier, M., Merville, M.P., Gielen, J., Piette, J., Bours, V., Chariot, A., 2003. Cytoplasmic IkappaBalpha increases NF-kappaB-independent transcription through binding to histone deacetylase (HDAC) 1 and HDAC3. J. Biol. Chem. 278, 46541-46548.

Waddington, C.H., 1942. The epigenotype. Endeavour 1, 18-20.

Wang, Z., Zang, C., Rosenfeld, J.A., Schones, D.E., Barski, A., Cuddapah, S., Cui, K., Roh, T.Y., Peng, W., Zhang, M.Q., Zhao, K., 2008. Combinatorial patterns of histone acetylations and methylations in the human genome. Nat. Genet. 40, 897-903.

West, A.E., Griffith, E.C., Greenberg, M.E., 2002. Regulation of transcription factors by neuronal activity. Nat. Rev. Neurosci. 3, 921-931.

Yamamoto, Y., Verma, U.N., Prajapati, S., Kwak, Y.T., Gaynor, R.B., 2003. Histone $\mathrm{H} 3$ phosphorylation by IKK-alpha is critical for cytokine-induced gene expression. Nature 423, 655-659.

Yeung, F., Hoberg, J.E., Ramsey, C.S., Keller, M.D., Jones, D.R., Frye, R.A., Mayo, M.W., 2004. Modulation of NF-kappaB-dependent transcription and cell survival by the SIRT1 deacetylase. EMBO J. 23, 2369-2380.

Yu, Z., Zhou, D., Bruce-Keller, A.J., Kindy, M.S., Mattson, M.P., 1999. Lack of the p50 subunit of nuclear factor-kappaB increases the vulnerability of hippocampal neurons to excitotoxic injury. J. Neurosci. 19, 8856-8865.

Zhong, H., Voll, R.E., Ghosh, S., 1998. Phosphorylation of NF-kappa B p65 by PKA stimulates transcriptional activity by promoting a novel bivalent interaction with the coactivator CBP/p300. Mol. Cell 1, 661-671.

Zhong, H., May, M.J., Jimi, E., Ghosh, S., 2002. The phosphorylation status of nuclear NF-kappa B determines its association with CBP/p300 or HDAC-1. Mol. Cell 9, 625-636. 